\title{
Level, distribution and sources of plutonium in the coastal areas of China
}

\section{Zhang, Weichao; Hou, Xiaolin}

\section{Published in:}

Chemosphere

Link to article, DOI:

10.1016/j.chemosphere.2019.05.094

Publication date:

2019

Document Version

Peer reviewed version

Link back to DTU Orbit

Citation (APA):

Zhang, W., \& Hou, X. (2019). Level, distribution and sources of plutonium in the coastal areas of China. Chemosphere, 230, 587-595. https://doi.org/10.1016/j.chemosphere.2019.05.094

\section{General rights}

Copyright and moral rights for the publications made accessible in the public portal are retained by the authors and/or other copyright owners and it is a condition of accessing publications that users recognise and abide by the legal requirements associated with these rights.

- Users may download and print one copy of any publication from the public portal for the purpose of private study or research.

- You may not further distribute the material or use it for any profit-making activity or commercial gain

- You may freely distribute the URL identifying the publication in the public portal

If you believe that this document breaches copyright please contact us providing details, and we will remove access to the work immediately and investigate your claim. 


\section{Level, distribution and sources of plutonium in the coastal}

2

3

4

5

61 State Key Laboratory of Loess and Quaternary Geology, Shaanxi Key Laboratory of

7 Accelerator Mass Spectrometry Technology and Application, Xi'an AMS Center,

8 Institute of Earth Environment, Chinese Academy of Sciences, Xi'an, China

92 Center for Nuclear Technologies, Technical University of Denmark, DTU Nutech, 10 Roskilde, Denmark

113 CAS Center of Excellence in Quaternary Science and Global Change, Xi' an, China 124 University of Chinese Academy of Sciences, Beijing, China

135 Open Studio for Oceanic-Continental Climate and Environment Changes, Pilot 14 National Laboratory for Marine Science and Technology (Qingdao), Qingdao 15266061 , China

16

17

18

19

20

21

* Corresponding author at: Technical University of Denmark, Center for Nuclear Technologies, Frederiksborgvej 399, Roskilde, Denmark, E-mail: xiho@dtu.dk (Xiaolin Hou). Fax:45 46775357 
22 Abstract: Plutonium is an important radioactive element in view of its biological 23 toxicity and environmental impact. The two most important isotopes of plutonium,

$24{ }^{239} \mathrm{Pu}$ and ${ }^{240} \mathrm{Pu}$, in the surface soil from the coastal area of China were determined using radiochemical separation combined with inductively coupled plasma mass spectrometry (ICP-MS) measurement. The average of the measured ${ }^{240} \mathrm{Pu} /{ }^{239} \mathrm{Pu}$ atomic ratios in all these samples is $0.186 \pm 0.021$, which is in good agreement with the ratio of global fallout of the nuclear weapons tests. This indicates that the major source of plutonium in this region is global fallout, and there is no measurable release of plutonium from any nuclear power plant along the coast of China. The ${ }^{239,240} \mathrm{Pu}$ concentrations in all 71 soil samples range from $0.002 \mathrm{mBq} / \mathrm{g}$ to $0.670 \mathrm{mBq} / \mathrm{g}$, which fall in the range of the reported values in the background area not directly influenced by nuclear activities. The anthropogenic disturbance of sampling sites, vegetation coverage of land, precipitation rate and organic substance content and erosion of soil have significant influence on the level of plutonium in the surface soil.

Keyword: Plutonium isotopes; source term of plutonium; spatial distribution; environmental impact; coastal areas of China

\section{Introduction}

Plutonium has been released to the environment by human nuclear activities, such as nuclear weapons tests, nuclear accidents, satellite accidents and nuclear fuel reprocessing plants (Qiao et al., 2009). Among them, the nuclear weapons tests released $6.5 \times 10^{15} \mathrm{~Bq}^{239} \mathrm{Pu}$ and $4.4 \times 10^{15} \mathrm{~Bq}^{240} \mathrm{Pu}$, making it the dominant source of ${ }^{239} \mathrm{Pu}$ and ${ }^{240} \mathrm{Pu}$ in the environment (UNSCEAR, 1993). ${ }^{239} \mathrm{Pu}$ and ${ }^{240} \mathrm{Pu}$ are produced through sequential neutron activation reactions of uranium, this makes the ${ }^{240} \mathrm{Pu} /{ }^{239} \mathrm{Pu}$ atomic 
ratios different in the samples with the different source of plutonium. The reported ${ }^{240} \mathrm{Pu} /{ }^{239} \mathrm{Pu}$ atomic ratios are $0.178 \pm 0.023$ for releases from global fallout of the nuclear weapons tests (Kelley et al., 1999), 0.01-0.07 for fuel of nuclear weapons (measured in the debris of plutonium fuel of nuclear weapons) (Eriksson et al. 2008), 0.23-0.67 for nuclear power plants (Warneke, 2002a; 2002b), 0.386-0.412 for releases from the Chernobyl accidnet (Boulyga et al., 1997; Wendt et al., 1999) and 0.323-0.330 for releases from the Fukushima accident (Zheng et al., 2013). This feature makes the ${ }^{240} \mathrm{Pu} /{ }^{239} \mathrm{Pu}$ ratio a unique fingerprint to identify the source of the radioactive substance in the environment and for nuclear forencics.

${ }^{239} \mathrm{Pu}\left(\mathrm{T}^{1} / 2=24 \mathrm{kyr}\right)$ and ${ }^{240} \mathrm{Pu}\left(\mathrm{T}^{1} / 2=6.5 \mathrm{kyr}\right)$ are the two most important isotopes of plutonium in the environment. Both of them are alpha emitters with high radiological toxicities, and therefore one of most important hazardous pollutant in the environment. Based on the unique ratios of ${ }^{240} \mathrm{Pu} /{ }^{239} \mathrm{Pu}$ for the specific sources, plutonium isotopes in the environment have been used to investigate the source of radioactive substance and evaluate their environmental impact. The overall deposition of plutonium on the land from nuclear weapons tests and local releases of plutonium from nuclear activities makes plutonium isotopes a good tracer for investigation of soil erosion, redistribution of sediment, and water circulation in the ocean (Xu et al. 2013; Wang et al. 2017). An investigation on plutonium isotope in soil and sediment samples from the Liaodong Bay in northeast China and north Yellow Sea have been carried out to investigation of the soil erosion and input and transport of suspended particles/sediment in the seas (Xu et al. 2013, 2015, 2018). A level and distribution of ${ }^{240} \mathrm{Pu}$ and ${ }^{239} \mathrm{Pu}$ in soil in a large area in China have been investigated to identify the sources of the anthropogenic radioactive substances and their impact to the environemnt in China (Liaoning, Hebei, Shandong, Fujian, Guangxi, Guangdong, Zhejiang) (Xing, 2015; 
Dong, 2010; Ni et al. 2018).

Rapid increased numbers of nuclear power plants were built in China in the past 20 years. To January 2019, 45 nuclear power reactors with the total capacity of 42.8 GW have been instilled and operated in China, and more than 11 nuclear power reactors are under construction (IAEA, 2019). All these nuclear power plants are located in the coastal area of China (Fig. 1). There is a big concern on the radiation impact of these nuclear power plants to the local environment. Although some investigation on the anthropogenic radionuclides including plutonium isotopes in the environment including the China have been reported, however, no systematic investigation of the anthropogenic radioactivity in the coastal area of China was reported.

This work aims to investigate the level, distribution and source of plutonium in the coastal areas of China, in order to assess the environmental impact of the nuclear power plants in this area, meanwhile to explore the influence of human activities and environmental and climate factors on the level and distribution of plutonium in the environment in thecoastal area of China. This is going to be implemented by analyzing surface soil samples collected from this area for ${ }^{239} \mathrm{Pu}$ and ${ }^{240} \mathrm{Pu}$ using radiochemical separation and ICP-MS measurement.

\section{Materials and Methods}

\subsection{Sampling}

In total 71 surface soil samples were collected in depth of $0-5 \mathrm{~cm}$ (in most of sites) from the coastal area in China in July 2014, July 2015, April 2016 and April 2017 (Fig 2 and Table 1). The sampling sites were normally selected in a flat area without visible disturbance. However, the land in some areas in Beijing, Tianjin, Hebei, Shandong, 
Jiangsu and Anhui province are highly cultivated by farming, it is difficult to find undisturbed sites. In this case, soil samples of 0-30 $\mathrm{cm}$ depth were collected using a stainless-steel soil core sampler of $7 \mathrm{~cm}$ in diameter and $30 \mathrm{~cm}$ in height. The surface soil samples of $5 \mathrm{~cm}$ depth were collected using a ring cutter of $7.0 \mathrm{~cm}$ in diameter and height of $5.0 \mathrm{~cm}$. The samples from 5 points in a triangle of $1 \mathrm{~m}$ between each point were collected at each site and mixed as one sample. The collected soil samples were sealed in plastic bags and transported to the laboratory for analysis.

The soil sample was first weighted and air dried after removal of big stones $(>5$ $\mathrm{mm})$ and vegetation roots. The samples were then dried in an oven at $150^{\circ} \mathrm{C}$ until constant weight. The dried samples were weighed, ground and sieved through an 80mesh sieve.

\subsection{Analytical method for determination of ${ }^{239} \mathrm{Pu}$ and ${ }^{240} \mathrm{Pu}$ in soil samples}

The soil samples were analyzed for ${ }^{239} \mathrm{Pu}$ and ${ }^{240} \mathrm{Pu}$ using radiochemical separation combined with ICP-MS/MS measurement. A brief description of the analytical method is presented here, and the detailed analytical method has been reported elsewhere (Xing et al., 2018). The dried and ground soil was ashed at $450^{\circ} \mathrm{C}$ overnight, the loss of the sample mass (loss of ignition) was recorded as approximate mass of the organic substance in the sample. After spiked $5.0 \mathrm{pg}$ of ${ }^{242} \mathrm{Pu}$ to the ashed sample as a chemical yield tracer, the sample was leached with $50 \mathrm{~mL}$ of aqua regia at $150^{\circ} \mathrm{C}$ for 0.5 hours and then $200^{\circ} \mathrm{C}$ for 2 hours. The leachate containing plutonium was separated from the residue by filtration through a glass fiber filter. Ammonium was added to the leachate to $\mathrm{pH}$ 8-9 to co-precipitate plutonium with $\mathrm{Fe}(\mathrm{OH})_{3}$. The precipitate was washed using $2 \mathrm{~mol} / \mathrm{L} \mathrm{NaOH}$ to remove amphoteric elements (such as Al, $\mathrm{V}$, etc.). The precipitate was 
then dissolved using $\mathrm{HCl}$, and plutonium in the solution was reduced to $\mathrm{Pu}^{3+}$ by addition

121 of $\mathrm{K}_{2} \mathrm{~S}_{2} \mathrm{O}_{5}$, and meanwhile iron was reduced to $\mathrm{Fe}^{2+}$. Ammonium was added to $\mathrm{pH}$ 8-9

122 to co-precipitate $\mathrm{Pu}(\mathrm{OH})_{3}$ with $\mathrm{Fe}(\mathrm{OH})_{2}$, which was separated by centrifuge. The

123 precipitate was dissolved with the concentrated $\mathrm{HNO}_{3}$, meanwhile $\mathrm{Pu}^{3+}$ was oxidized

124 to $\mathrm{Pu}^{4+}$ with $\mathrm{NO}_{2}^{-}$presented in the concentrated $\mathrm{HNO}_{3}$, and the solution was prepared

125 in $1.0 \mathrm{~mol} / \mathrm{L} \mathrm{HNO}_{3}$. The prepared sample solution was loaded to a $2 \mathrm{~mL}$ of TEVA

126 column which was conditioned using $1.0 \mathrm{~mol} / \mathrm{L} \mathrm{HNO}_{3}$. The column was rinsed with 1.0

$127 \mathrm{~mol} / \mathrm{L} \mathrm{HNO}_{3}$ and $6.0 \mathrm{~mol} / \mathrm{L} \mathrm{HCl}$ to remove the matric and interfering elements.

128 Plutonium adsorbed on the column was finally eluted with $0.1 \mathrm{~mol} / \mathrm{L} \mathrm{NH} \mathrm{N}_{2} \mathrm{OH} \cdot \mathrm{HCl}$ in

$1292 \mathrm{~mol} / \mathrm{L} \mathrm{HCl}$. The eluate of plutonium was evaporated to dryness, concentrated $\mathrm{HNO}_{3}$

130 was added and evaporated to dryness again to decompose and remove $\mathrm{NH}_{2} \mathrm{OH} \cdot \mathrm{HCl}$.

131 The residue was dissolved with $0.5 \mathrm{~mol} / \mathrm{L} \mathrm{HNO}_{3}$ and transferred to a counting tube in a

132 final volume of $3.5 \mathrm{~mL} .{ }^{239} \mathrm{Pu},{ }^{240} \mathrm{Pu}$ and ${ }^{242} \mathrm{Pu}$ in the prepared sample solutions were

133 measured using ICP-MS/MS (Agilent 8800 Agilent Technologies, Tokyo, Japan) using

$134 \mathrm{NH}_{3}-\mathrm{He}$ as a reaction gas. The detection limits of this method for ${ }^{239} \mathrm{Pu}$ and ${ }^{240} \mathrm{Pu}$ were

135 estimated to be $0.55 \mathrm{fg} / \mathrm{mL}$ for ${ }^{239} \mathrm{Pu}$ and $0.09 \mathrm{fg} / \mathrm{mL}$ for ${ }^{240} \mathrm{Pu}$ using the procedure blank

136 in $3.5 \mathrm{~mL} \mathrm{HNO}_{3}$ solution. The blank was subtracted from the measured results of

137 samples for calculation of the concentration of plutonium isotopes. A schematic

138 diagram of the analytical procedure is shown in Fig. 3. It should be mentioned that the

139 acid leaching method is suitable only for determination of global fallout plutonium in

140 environmental samples such as soil and sediment. For plutonium present as refractory

141 oxides, such as fallout in the close-in location of the nuclear weapons tests sites and

142 nuclear accidents, a full dissolution method such as borate fusion and acid dissolution

143 with HF is needed.

144 The above method was evaluated by analysis of soil (IAEA-327) and sediment 
145 (IAEA-327) reference material. The measured concentrations of ${ }^{239} \mathrm{Pu}(0.349 \pm 0.014$

$146 \mathrm{mBq} / \mathrm{g})$ and ${ }^{240} \mathrm{Pu}(0.247 \pm 0.011 \mathrm{mBq} / \mathrm{g})$ and ${ }^{240} \mathrm{Pu} /{ }^{239} \mathrm{Pu}$ atomic ratio $(0.192 \pm 0.012)$

147 for IAEA-327 are in good agreement with the reference values for ${ }^{239} \mathrm{Pu}(0.35 \pm 0.02$

$148 \mathrm{mBq} / \mathrm{g})$ and ${ }^{240} \mathrm{Pu}(0.25 \pm 0.02 \mathrm{mBq} / \mathrm{g})$ and ${ }^{240} \mathrm{Pu} /{ }^{239} \mathrm{Pu}$ atomic ratio $(0.19 \pm 0.02)($ Baeza

149 et al., 2006). At the same time, the measured concentrations ${ }^{239} \mathrm{Pu}(1.887 \pm 0.063 \mathrm{mBq} / \mathrm{g})$

150 and ${ }^{240} \mathrm{Pu}(1.210 \pm 0.044 \mathrm{mBq} / \mathrm{g})$ and ${ }^{240} \mathrm{Pu} /{ }^{239} \mathrm{Pu}$ atomic ratio $(0.175 \pm 0.009)$ in IAEA-

151385 sediment are also agree well with the reference values for ${ }^{239} \mathrm{Pu}(1.79 \pm 0.28 \mathrm{mBq} / \mathrm{g})$

152 and ${ }^{240} \mathrm{Pu}(1.15 \pm 0.14 \mathrm{mBq} / \mathrm{g})$ and ${ }^{240} \mathrm{Pu} /{ }^{239} \mathrm{Pu}$ atomic ratio $(0.174 \pm 0.032)$ (Xing et al.,

153 2018). Besides, the recoveries of plutonium measured by the spiked ${ }^{242} \mathrm{Pu}$ tracer range

154 from $75 \%$ to $95 \%$. The above results indicated that the analysis method for

155 determination of trace concentrations ${ }^{239} \mathrm{Pu}$ and ${ }^{240} \mathrm{Pu}$ in environmental samples is

156 reliable and accurate.

\section{$157 \quad 3$ Results and discussion}

\section{$158 \quad 3.1$ Level and distribution of plutonium isotopes in the coastal areas of China}

159 The concentrations ${ }^{239} \mathrm{Pu}$ and ${ }^{240} \mathrm{Pu}$ in 71 surface soil samples are shown in Table

160 1. Many data on the activity concentration of plutonium isotopes were reported for $161{ }^{239,240} \mathrm{Pu}$ (sum of ${ }^{239} \mathrm{Pu}$ and ${ }^{240} \mathrm{Pu}$ ), because the conventional method for determination 162 of ${ }^{239} \mathrm{Pu}$ and ${ }^{240} \mathrm{Pu}$ is alpha spectrometry, which could not discriminate ${ }^{239} \mathrm{Pu}$ from ${ }^{240} \mathrm{Pu}$ 163 due to their very close energy of alpha emissions. To easily compare with the reported 164 values, the concentrations of ${ }^{239,240} \mathrm{Pu}$ in the analytical samples were calculated as ${ }^{239} \mathrm{Pu}$ $165+{ }^{240} \mathrm{Pu}$. The results (Fig. 4) show that concentrations of ${ }^{239,240} \mathrm{Pu}$ are $(0.002-0.670)$ $166 \mathrm{mBq} / \mathrm{g}$, with two orders of magnitude variation. The concentration of ${ }^{239,240} \mathrm{Pu}$ in soil in 167 the background place without direct influence by nuclear activities have been reported 168 to be (0.057-0.313) mBq/g in northeast China (Xing, 2015; Xu et al., 2015), (0.046169 0.678) mBq/g in north China (Dong, 2010; Xing, 2015), (0.042-0.641) mBq/g in east 
170 China, (0.033-0.173) mBq/g in south China (Xing, 2015), and (0.011-0.391) mBq/g in

171 the similar latitude from other areas in China without human nuclear activity (Dong,

172 2010; Wang et al., 2013; Bu et al., 2014; Xing, 2015). The measured ${ }^{239,240} \mathrm{Pu}$

173 concentrations in this work fall into the reported range $(0.042-0.678) \mathrm{mBq} / \mathrm{g}$ in China

174 (Bu et al., 2014; Dong, 2010; Wang et al., 2013; Xing, 2015).

175 According to latitude of the sampling sites, average values of ${ }^{239,240} \mathrm{Pu}$

176 concentration in surface soil samples from each five-degree latitude band in a range of

$17720-45^{\circ} \mathrm{N}$ are calculated to be $0.059 \mathrm{mBq} / \mathrm{g}$ in $20-25^{\circ} \mathrm{N}, 0.117 \mathrm{mBq} / \mathrm{g}$ in $25-30{ }^{\circ} \mathrm{N}$,

$1780.067 \mathrm{mBq} / \mathrm{g}$ in $30-35^{\circ} \mathrm{N}, 0.108 \mathrm{mBq} / \mathrm{g}$ in $35-40^{\circ} \mathrm{N}$ and $0.160 \mathrm{mBq} / \mathrm{g}$ in $40-45^{\circ} \mathrm{N}$ band.

179 Low ${ }^{239,}{ }^{240} \mathrm{Pu}$ concentrations in the surface soil are observed in the latitude bands of

$180 \quad 20-25$ and $30-35^{\circ} \mathrm{N}$, and the highest area is measured in the band of $40-45^{\circ} \mathrm{N}$. This

181 trend does not well agree with the reported distribution of the most anthropogenic

182 radionuclides from the global fallout of the nuclear weapons tests (Hardy et al. 1973,

183 UNSCEAR, 2000, Aoyama et al. 2006), in which a gradually increased concentrations

184 of fallout radionuclides in the environment with the latitude in $20-45^{\circ} \mathrm{N}$ were reported.

185 The sites of the most atmospheric nuclear weapons tests were located in the mid-high

186 latitude in the North Hemisphere $\left(40-50^{\circ} \mathrm{N}\right)$. The radioactive substance was released to

187 the troposphere and injected to the stratosphere. The debris released to the troposphere

188 is mainly deposited locally, especially for the relatively large particles forming close-in

189 deposition, gaseous radionuclides and small particles transported to the upper

190 troposphere were dispersed to a relative larger distance. The radioactive substances

191 injected to the stratosphere and upper troposphere are mainly from large explosion

192 equivalent explosion, especially those thermonuclear devices, these substances were

193 mainly dispersed in the similar latitude due to the rotation of the earth, although some

194 fraction in the stratosphere was also dispersed cross the latitude, even cross the 
hemisphere. All these caused a high deposition of the fallout of nuclear weapons test in the middle and high latitude in the North Hemisphere. Such distribution trend of global fallout has been observed all over the world (UNSCEAR, 2000).

The lowest ${ }^{239,240} \mathrm{Pu}$ concentrations in surface soil $(0.003-0.116 \mathrm{mBq} / \mathrm{g}$ with an average of $0.059 \mathrm{mBq} / \mathrm{g}$ ) was observed in the area of the lowest latitude of $20-25^{\circ} \mathrm{N}$, and highest ${ }^{239,240} \mathrm{Pu}$ concentrations $(0.031-0.670 \mathrm{mBq} / \mathrm{g}$ with an average of 0.160 $\mathrm{mBq} / \mathrm{g}$ ) in the area of the highest latitude of $40-45^{\circ} \mathrm{N}$ in the entire investigation area of $20-45^{\circ} \mathrm{N}$. This variation follows the general distribution of the global fallout of the nuclear weapons tests all over the world (UNSCEAR, 2000). However, a relatively low ${ }^{239,240} \mathrm{Pu}$ concentrations in surface soil $(0.002-0.122 \mathrm{mBq} / \mathrm{g}$ with an average of 0.067 $\mathrm{mBq} / \mathrm{g}$ ) was observed in the area of $30-35^{\circ} \mathrm{N}$ compared to those observed in the lower latitude area in $25-30^{\circ} \mathrm{N}(0.004-0.223 \mathrm{mBq} / \mathrm{g}$ with an average of $0.117 \mathrm{mBq} / \mathrm{g})$ and the higher latitude area in $35-40^{\circ} \mathrm{N}(0.009-0.151 \mathrm{mBq} / \mathrm{g}$ with an average of $0.108 \mathrm{mBq} / \mathrm{g})$. This might be attributed disturbance of human activity in these sites. The soil samples in the latitude band of $30-35^{\circ} \mathrm{N}$ were mainly collected from agriculture land because of high cultivation in this area and difficulty to find undisturbed site. In these sites, the deposited plutonium was extensively mixed in the top $30 \mathrm{~cm}$ layer during the cultivation activity, and therefore the upper $30 \mathrm{~cm}$ soil was collected for analysis (Table 1). A relatively homogenous distribution of anthropogenic radionuclides $\left({ }^{137} \mathrm{Cs},{ }^{239} \mathrm{Pu},{ }^{240} \mathrm{Pu}\right)$ has been reported in the agriculture land because of the periodic mixture of the soil $(\mathrm{Xu}$ et al. 2015), this caused a low concentration of ${ }^{239,}{ }^{240} \mathrm{Pu}$ in the surface soil collected from the cultivated land compared to those from the undisturbed sites (Xu et al., 2015). Relatively high ${ }^{239,240} \mathrm{Pu}$ concentrations were observed in the surface soil collected in the area in $25-30^{\circ} \mathrm{N}(0.004-0.223 \mathrm{mBq} / \mathrm{g}$ with an average of $0.117 \mathrm{mBq} / \mathrm{g})$ compared to those collected in the area of higher latitude of $35-40^{\circ} \mathrm{N}(0.009-0.151 \mathrm{mBq} / \mathrm{g}$ with an 
average of $0.108 \mathrm{mBq} / \mathrm{g}$ ). This might be attributed to the vegetation coverage and

221 organic substance content in the soil. The sampling sites in the area of $25-30^{\circ} \mathrm{N}$ are mainly located in forest with high vegetation coverage, which prevents from the erosion of the soil, therefore well reserved plutonium in the soil (Li et al., 2014). Relative higher organic content (ignition loss) were measured in the samples in the area of $25-30^{\circ} \mathrm{N}$ (4$2258 \%$ ) compared to the sites of other areas. The fractionation analysis has shown that large 226 fraction of plutonium is associated with organic substances in the soil (Qiao et al. 2012). 227 mainly in a stable complex with humic and fulvic acids in soil (Lee et al. 1997). The 228 high content of organic substance can help the fixation of plutonium after it deposited 229 and entered the soil, and reduce the migration of plutonium the deep soil.

230 The highest ${ }^{239,240} \mathrm{Pu}$ concentration of $0.670 \mathrm{mBq} / \mathrm{g}$ was observed in the sample 231 S14152, which was collected at Zhangjiakou in Hebei province $\left(41.2^{\circ} \mathrm{N}, 116.2{ }^{\circ} \mathrm{E}\right)$ 232 with a precipitation rate of $385 \mathrm{~mm} / \mathrm{yr}$. It has been reported that both gaseous and 233 particle associated radionuclides can be effectively trapped and washed out from the 234 atmosphere to be deposited to the earth, therefore wet deposition is the major deposition 235 of radionuclides from the atmosphere (UNSCEAR, 2000). Combined with a relatively 236 high latitude of this site $\left(41.2^{\circ} \mathrm{N}\right)$, corresponding to the high level of plutonium released 237 during the atmospheric nuclear weapons test in 1945-1980 mainly in the high latitude 238 of North Hemisphere, a high fallout level of anthropogenic radionuclides from the 239 nuclear weapons tests is expected, causing a high ${ }^{239,}{ }^{240} \mathrm{Pu}$ level in this site. A similar 240 high ${ }^{239,240} \mathrm{Pu}$ concentration in surface soil $(0.687 \mathrm{mBq} / \mathrm{g})$ was also reported in Beijing, 241 in the same latitude in Beijing (Dong, 2010). In addition, this sampling site is located 242 in a forest, and a high organic substance content of $11.9 \%$ was measured in this soil, 243 therefore a less loss of plutonium by soil erosion and less migration of plutonium in the 244 surface soil are expected in this site, which helps to reserve the deposited plutonium in 
the surface soil in this site.

The lowest ${ }^{239,240} \mathrm{Pu}$ concentrations were observed in soil sample S15097 (0.002 $\mathrm{mBq} / \mathrm{g})$ collected at Taizhou in Jiangsu province $\left(32.3^{\circ} \mathrm{N}, 120.0^{\circ} \mathrm{E}\right)$ with a relative

248 high precipitation rate of $1022 \mathrm{~mm} / \mathrm{yr}(\mathrm{Xu}, 2017)$ and $\mathrm{S} 16016(0.002 \mathrm{mBq} / \mathrm{g})$ collected at Shangrao in Jiangxi province $\left(28.4^{\circ} \mathrm{N}, 117.7^{\circ} \mathrm{E}\right)$ with a relatively high precipitation rate of $>1500 \mathrm{~mm} / \mathrm{yr}$. These two samples are sandy soil with very low organic substance content (1.1\% and $2.7 \%)$ and the two sites were also less covered by vegetation, all 252 these features cause a high loss of surface soil by erosion, and less fixation of plutonium 253 resulting in a high migration of plutonium from the surface soil. Combined with the 254 less deposition in the low latitude area, a low ${ }^{239,240} \mathrm{Pu}$ concentration occurred in these 255 soil samples.

\subsection{Sources of plutonium in the environment in the coastal area of China}

${ }^{240} \mathrm{Pu} /{ }^{239} \mathrm{Pu}$ atomic ratios in the surface soil samples collected in the coastal area of

259 China were measured to be $0.154-0.227$ with an average of 0.186 (Fig. 5), which is 260 in a good well agreement with the reported ratio of global fallout of nuclear weapons 261 tests $(0.178 \pm 0.023)$ (Kelley et al., 1999), but significantly different with the values in 262 the fuel of nuclear weapons and the close-in deposition of nuclear weapons tests $(0.01-$ 263 0.07) (Eriksson et al. 2008), releases from the Chernobyl accident (0.386-0.412) 264 (Boulyga et al., 1997; Wendt et al., 1999), Fukushima accident (0.323-0.330) (Zheng et 265 al., 2013) and some NPP (0.23-0.67) (Warneke, 2002a). These results indicate that the 266 plutonium in the surface soil in the study area is dominantly originated from the global 267 fallout of the nuclear weapons tests in 1945-1980.

268 Nuclear accident in Chernobyl happened in April 1986 had released a large amount 269 of radioactive substances into the environment, besides the deposition in the local 
region, the radioactive plume was also dispersed to large area and deposition mainly in 271 the Europe (Levi, 1991; Muramatsu et al., 2000). Meanwhile, low level of Chernobyl 272 derived ${ }^{131} \mathrm{I}$ and ${ }^{137} \mathrm{Cs}$ were also measured in China, mainly in North China. Although 273 some amount of plutonium was also released from the Chernobyl nuclear accident and 274 observed in the heavy contaminated area in Ukraine, Belorussia and Russia 275 (UNSCEAR, 2000; Thakur et al. 2017). No Chernobyl derived plutonium was reported in China and the very low level of Chernobyl derived plutonium was observed in the 277 air sample in Japan in a short period after the Chernobyl accident (Hirose et al. 1994), 278 because plutonium released from the Chernobyl was mainly associated with particles, 279 and deposited in the close-in place. Fukushima nuclear accident happened in 2011 had 280 also released a mass of radioactive substances into the environment, but plutonium 281 derived from Fukushima nuclear accident was detected only in some samples around 282 Fukushima Daiichi NPP $(<20 \mathrm{~km})$ (Zheng et al., 2013), no Fukushima derived 283 plutonium was observed in other region including China. In addition, only lower level 284 of Fukushima derived ${ }^{131} \mathrm{I}$ and ${ }^{137} \mathrm{Cs}$ was detected in China during the accident due to 285 the dominant westwards wind. Therefore, the contribution of two nuclear accidents to 286 plutonium in the soil samples in the study area can be neglected.

287 The sampling sites are more than $2000 \mathrm{~km}$ far to the nearest nuclear weapons tests 288 site at Lop Nor. Although some radioactive substances released from the weapons tests 289 at this site in 1964-1980 might be transported and deposited in the sampling site due to 290 the dominant westerlies in North China, the contribution of the close-in deposition of 291 plutonium at Lop Nor to plutonium in the sampling region might be limited because of 292 the particles associated feature and long distance. The ${ }^{240} \mathrm{Pu} /{ }^{239} \mathrm{Pu}$ atomic ratios, 293 reported in the soil from other area in China, such as Shangqiu (0.186-0.218) (Wang et 294 al., 2013), Puyang (0.179-0.189) (Wang et al., 2013), Jingmen (0.170-0.211) (Dong, 

2013), Lanzhou (0.168-0.192) (Zheng et al., 2009) and Chengdu (0.184-0.223) (Dong, 2010) confirmed no detectable effect of plutonium in soil in the background area in China. The ${ }^{240} \mathrm{Pu} /{ }^{239} \mathrm{Pu}$ atomic ratios in the sediment from Lake Hongfeng (0.162-0.213)

299 (Zheng et al., 2008b), Lake Poyang (0.185-0.192) (Liao et al., 2008), Lake Shuangta 300 (0.160-0.192) (Wu et al., 2010), Lake Chenghai (0.164-0.223) (Zheng et al., 2008a), 301 Dianchi (0.164-0.187) (Shi, 2015) and Lake Fuxian (0.173-0.201) (Shi, 2015) in China 302 also showed no detectable influence on the plutonium deposition in these areas. These 303 data suggest that the close-in deposition of Chinese nuclear weapons tests have a limited 304 influence on the plutonium in the soil in the downwind area far away from nuclear 305 activity areas.

306 The analytical results of ${ }^{240} \mathrm{Pu} /{ }^{239} \mathrm{Pu}$ ratio in the surface soil collected in the coastal 307 areas of China and the above discussion indicate that except the global fallout of 308 atmospheric nuclear weapons tests before 1980, no other source of plutonium in this 309 region is detectable. This also implies that no detectable plutonium was released from 310 the nuclear power reactors along the coastal areas of China, confirming the safe 311 operation of these nuclear power plants.

\section{Conclusion and perspectives}

314 Based on the results and discussion above, it can be concluded: (1) The concentrations 315 of ${ }^{239,240} \mathrm{Pu}$ in the surface soil in the coastal area of China ranging from $0.002 \mathrm{mBq} / \mathrm{g}$ to $3160.670 \mathrm{mBq} / \mathrm{g}$ is comparable to the values reported in other locations in China and other 317 similar latitude place of background areas. The distribution of ${ }^{239,240} \mathrm{Pu}$ concentration in 318 the surface soil depends on the sampling site related to the deposition level of anthropogenic radionuclides due to the most of nuclear weapons tests sites located in 
the middle and high latitude area in the North Hemisphere. The vegetation coverage

321 and organic substance content in the soil help the reservation of deposited plutonium in

322 the surface soil. (2) Plutonium in the environment in the coastal area of China is

323 dominantly originated from the global fallout of atmospheric nuclear weapons tests

324 with the typical ${ }^{240} \mathrm{Pu} /{ }^{239} \mathrm{Pu}$ ratio of 0.18 , contribution of the other sources to the

325 plutonium in this region is negligible. (3) There is no detectable effect of the NPPs

326 along the coast of China to the environment, in view of the plutonium. The analytical

327 results of this work provide valuable baseline values of plutonium isotopes in the

328 environment in the coastal area of China, which will be very useful for the evaluation

329 of the impact of NPPs along the coast of China because of the rapid increased

330 installation and operation of nuclear power plants in this region in the past years as well

331 as in the coming years.

\section{Declaration of interest}

335 None.

\section{Acknowledgments}

338 This work was supported by the National Natural Science Foundation of China 339 (11605206, 11875261, 91643206 and 41603125), the Ministry of Science and 340 Technology of China (2015FY110800), Chinese Academy of Sciences 341 (132B61KYSB20180003) and National Research Program for Key Issues in Air 342 Pollution Control (DQGG0105-02). Authors thank all colleagues in the environmental 343 radioactivity group in the Xi'an AMS center, Institute of Earth Environment, CAS for 
344 their helps in the sampling and sample pre-treatment.

\section{Reference}

348 Aoyama, M., Hirose, K., Igarashi, Y., 2006. Re-construction and updating our understanding on the global weapons tests ${ }^{137}$ Cs fallout. J. Environ. Monit. 8, 431438. https://doi.org/10.1039/b512601k

Baeza A., Guillén F.J., Salas A., Manjón J.L., 2006. Distribution of radionuclides in different parts of a mushroom: Influence of the degree of maturity[J]. Sci. Total Environ., 359(1-3): 255-266. https://doi.org/10.1016/j.scitotenv.2005.05.015

Boulyga, S.F., Erdmann, N., Funk, H., Kievets, M.K., Lomonosova, E.M., Mansel, A., Trautmann, N., Yaroshevich, O.I., Zhu, I.V., 1997. Determination of isotopic composition of plutonium in hot particles of the Chernobyl area. Radiat. Meas. 28, 349-352. https://doi.org/10.1016/S1350-4487(97)00098-X

Bu, W., Zheng, J., Guo, Q., Uchida, S., 2014. Vertical distribution and migration of global fallout $\mathrm{Pu}$ in forest soils in southwestern China. J. Environ. Radioact. 136, 174-180. https://doi.org/10.1016/j.jenvrad.2014.06.010

Dong, W., 2010. Distribution and Behavior of Pu Isotopes in the Environment. Peking University. (in Chinese)

Eriksson, M., Lindahl, P., Roos, P., Dahlgaard, H., Holm, E., 2008. U, Pu, and Am nuclear signatures of the Thule hydrogen bomb debris. Environ. Sci. Technol. 42,

366 Hardy, E.P., Krey, P.W., Volchok, H.L., 1973. Global Inventory and Distribution of 367 Fallout Plutonium. 241, 444-445. https://doi.org/10.1038/241444a0 
368 Hirose, K., Takatani, S., Aoyama, M., 1994. Deposition of ${ }^{90} \mathrm{Sr}$ and plutonium isotopes 369 derived from the Chernobyl accident in Japan. J. Radioanal. Nucl. Chem., 182, 349$370 \quad 358$. https://doi.org/10.1007/BF02037511

371 IAEA, 2019. Power reactor information system.

372 https://pris.iaea.org/PRIS/WorldStatistics/ShutdownReactorsByCountry.aspx

373 Kelley, J.M., Bond, L.A., Beasley, T.M., 1999. Global distribution of Pu isotopes and $374 \quad{ }^{237} \mathrm{~Np}$. Sci. Total Environ. 237-238, 483-500. https://doi.org/10.1016/S0048$375 \quad \underline{9697(99) 00160-6}$

376 Lee, M.H., Lee, C.W., Boo, B.H., 1997. Distribution and characteristics of ${ }^{239,240} \mathrm{Pu}$ and $377{ }^{137} \mathrm{Cs}$ in the soil of Korea. J. Environ. Radioact. 37, 1-16. $378 \quad$ https://doi.org/10.1016/S0265-931X(96)00080-X

379 Levi, H.W., 1991. Radioactive deposition in Europe after the Chernobyl accident and 380 its long-term consequences. Ecol. Res. 6, 201-216. $381 \quad$ https://doi.org/10.1007/bf02347162

382 Li, Q., Liu, G.-b., Xu, M., Zhang, Z., 2014. Relationship of Soil Erodibility, Soil 383 Physical Properties, and Root Biomass with the Age of caragana Korshinskii Kom. 384 Plantations on the Hilly Loess Plateau, China. Arid Land Res. Manag. 28, 311-324. $385 \quad$ https://doi.org/10.1080/15324982.2013.855957

386 Liao, H., Zheng, J., Wu, F., Yamada, M., Tan, M., Chen, J., 2008. Determination of 387 plutonium isotopes in freshwater lake sediments by sector-field ICP-MS after 388 separation using ion-exchange chromatography. Appl. Radiat. Isot. 66, 1138-1145. $389 \quad$ https://doi.org/10.1016/j.apradiso.2008.01.001

390 Muramatsu, Y., Rühm, W., Yoshida, S., Tagami, K., Uchida, S., Wirth, E., 2000. 391 Concentrations of ${ }^{239} \mathrm{Pu}$ and ${ }^{240} \mathrm{Pu}$ and Their Isotopic Ratios Determined by ICP392 MS in Soils Collected from the Chernobyl 30-km Zone. Environ. Sci. Technol. 34, 
394 Ni, Y., Wang, Z., Guo, Q., Zheng, J., Li, S., Lin, J., Tan, Z., Huang, W., 2018. Distinctive distributions and migrations of ${ }^{239+240} \mathrm{Pu}$ and ${ }^{241} \mathrm{Am}$ in Chinese forest, grassland and desert soils.

Chemosphere

212 ,

1002-1009. https://doi.org/10.1016/j.chemosphere.2018.09.021

398 Qiao, J., Hou, X., Miró, M., Roos, P., 2009. Determination of plutonium isotopes in 399 waters and environmental solids: A review. $652, \quad 66-84$. https://doi.org/10.1016/j.aca.2009.03.010

Qiao, J.X., Hansen, V., Hou, X.L., Aldahan, A., Possnert, G., 2012. Speciation analysis of ${ }^{129} \mathrm{I},{ }^{137} \mathrm{Cs},{ }^{232} \mathrm{Th},{ }^{238} \mathrm{Pu},{ }^{239} \mathrm{Pu}$ and ${ }^{240} \mathrm{Pu}$ in environmental soil and sediment. Appl. Radiat. Iso. 70, 1698-1708. http://doi.org/10.1016/j.apradiso.2012.04.006

Shi, Y., 2015. Spatial distribution of lead, radio-cesium and plutonium in typical lake sediments and their application for recent chronology. Guizhou University. (in Chinese)

Thakur, P., Khaig, H., Salminen-Paatero, S., 2017. Plutonium in the atmosphere: A global perspective. J. Environ. Radioact. 175-176, 39-51. https://doi.org/10.1016/j.jenvrad.2017.04.008

UNSCEAR, 1993. Sources and effects of ionizing radiation.UNSCEAR 1993 Report 414 UNSCEAR, 2000. Sources and effects of ionizing radiation. Report to the General 415 Assembly, with Scientific Annexes. Volume II: Effects. United Nations Scientific 416 Committee on the Effects of Atomic Radiation, United Nations, New York, pp. 156160. 
418 Wang, Y., Wang, W., Shen, M., Tian, M., Zhou, X., Wu, W., Jin, Y., 2013. ${ }^{239+240} \mathrm{Pu}$ and

$419 \quad{ }^{137}$ Cs in Soils of Three Sites from Shanxi and Henan. Radiat. Prot 33, 124-128. (in $420 \quad$ Chinese)

421 Wang, J.L., Baskaran, M., Hou, X.L., Du, J.Z., Zhang, J., 2017. Historical changes in $422 \quad{ }^{239} \mathrm{Pu}$ and ${ }^{240} \mathrm{Pu}$ sources in sedimentary records in the East China Sea: Implications 423 for provenance and transporation. Earth Planet. Sci. Lett. 466, 32-42. https://doi.org/10.1016/j.eps1.2017.03.005

Warneke, T., 2002(a). High-precision isotope ratio measurements of uranium and plutonium in the environment. University of Southampton.

Warneke T, Croudace I.W., Warwick P.E., Taylor R.N., 2002(b). A new ground-level fallout record of uranium and plutonium isotopes for northern temperate latitudes[J]. Earth and Planetary Science Letters. 203(3-4): 1047-1057.

430 Wendt, K., Blaum, K., Bushaw, B.A., Grüning, C., Horn, R., Huber, G., Kratz, J.V., 431 Kunz, P., Müller, P., Nörtershäuser, W., Nunnemann, M., Passler, G., Schmitt, A., 432 Trautmann, N., Waldek, A., 1999. Recent developments in and applications of resonance ionization mass spectrometry. Anal. Bioanal. Chem. 364, 471-477. https://doi.org/10.1007/s002160051370

Wu, J.W., Dai, M.H., Xu, Y., Zheng J., 2018. Source and accumulation of plutonium in a large western Pacific marginal sea: The South China Sea. Sci. Total Environ. 610611, 200-211. https://doi.org/10.1016/j.scitotenv.2017.07.226

Wu, F., Zheng, J., Liao, H., Yamada, M., 2010. Vertical Distributions of Plutonium and ${ }^{137}$ Cs in Lacustrine Sediments in Northwestern China: Quantifying Sediment Accumulation Rates and Source Identifications. Environ. Sci. Technol. 44, 2911-

442 Xing, S., 2015. Trace application of long-lived radionuclides ${ }^{239,240} \mathrm{Pu}$ and ${ }^{129} \mathrm{I}$ in the 
444 Xing, S., Zhang, W., Qiao, J., Hou, X., 2018. Determination of ultra-low level 445 plutonium isotopes $\left({ }^{239} \mathrm{Pu},{ }^{240} \mathrm{Pu}\right)$ in environmental samples with high uranium. 446 Talanta 187, 357-364. https://doi.org/10.1016/j.talanta.2018.05.051

$447 \mathrm{Xu}, \mathrm{L} ., 2$ 2017. Analysis of precipitation characteristics in Taizhou from 2011 to 2015. 448 Pollut. Control Technol. 30, 53-55. (in Chinese)

449 Xu, Y., Qiao, J., Pan, S., Hou, X., Roos, P., Cao, L., 2015. Plutonium as a tracer for soil 450 erosion assessment in northeast China. Sci. Total Environ. 511, 176-185. $451 \quad$ https://doi.org/10.1016/j.scitotenv.2014.12.006

452 Xu Y.H., Qiao J.X., Hou X.L.*, Pan S.M. Plutonium in soils from Northeast China and 453 its potential application for evaluation of soil erosion, Scientific Reports, 2013, 3, $454 \quad 3506: 1-8$. https://doi.org/10.1038/srep03506

455 Xu Y.H., Pan S.M., Gao J.H, Hou X.L., Ma Y.F., Hao Y.P. Sedimentary record of 456 plutonium in the North Yellow Sea and the response to catchment environmental 457 changes of inflow rivers. Chemosphere, 2018, 207:130-138. 458 https://doi.org/10.1016/j.chemosphere.2018.05.082

459 Zheng, J., Liao, H., Wu, F., Yamada, M., Fu, P., Liu, C., Wan, G., 2008a. Vertical 460 distributions of ${ }^{239+240} \mathrm{Pu}$ activity and ${ }^{240} \mathrm{Pu} /{ }^{239} \mathrm{Pu}$ atom ratio in sediment core of Lake 461 Chenghai, SW China. J. Radioanal. Nucl. Chem. 275, 37-42. $462 \quad$ https://doi.org/10.1007/s10967-006-7001-2

463 Zheng, J., Tagami, K., Uchida, S., 2013. Release of Plutonium Isotopes into the 464 Environment from the Fukushima Daiichi Nuclear Power Plant Accident: What Is 465 Known and What Needs to Be Known. Environ. Sci. Technol. 47, 9584-9595. $466 \quad$ https://doi.org/10.1021/es402212v

467 Zheng, J., Wu, F., Yamada, M., Liao, H., Liu, C., Wan, G., 2008b. Global fallout Pu 

and its isotopic composition in soils of Gansu in northwestern China. J. Environ.

473

474

475

476

477

478

479

480

481

482

483

484

485

486

487
Table 1 Analytical results of ${ }^{240} \mathrm{Pu}$ and ${ }^{239} \mathrm{Pu}$ concentration in the surface soil samples collected from coastal areas in China

\section{Caption of figures}

Fig. 1 Location of nuclear power plants and nuclear power units in operation and under construction in China until January 2019 (based on the data in IAEA, 2019)

Fig. 2 Sampling sites of surface soil samples in the coastal areas of China

Fig. 3 Schematic diagram of analytical procedure for determination of Pu isotopes in soil samples

Fig. 4 Distribution of ${ }^{239,}{ }^{240} \mathrm{Pu}$ concentrations in surface soil in the coastal areas of China

Fig. 5 Distribution of ${ }^{240} \mathrm{Pu} /{ }^{239} \mathrm{Pu}$ atomic ratio in surface soil in the coastal areas of China 
498 